\title{
Social Responsibility of Subjects of Educational Activity in the Digital Educational Environment
}

\author{
Polina Vysotskaya ${ }^{1},{ }^{*}$ Igor' Gajdamashko $^{1}$, Elena Klimova ${ }^{1}$, Yuliya Kuleshova ${ }^{1}$ \\ ${ }^{1}$ Moscow Regional State University, Russia \\ *Email:vvap512@mail.ru
}

\begin{abstract}
In the introduction of this work, the risks and problematic issues related to digital education are considered, and the impact on students and the perception of information during distance learning classes are reviewed. The study aimed to identify the level of social responsibility of subjects of educational activities. Its digital format determines an additional factor influencing the success of the training. Research methods: expert interviews, content analysis, analysis of results of operations. In the space of digital education, the trend of changing roles is highlighted, and qualitative changes in the field of education are reflected in connection with the transition to more active use of distance learning in Russian universities. Features of training of students of generation "Z" are defined. The role of social responsibility in educational activities is revealed, and its levels are determined. The results of the empirical study allowed us to develop normative models of interaction between subjects of educational activity in the digital educational environment: compulsory, resource, counter and background. The specific features of each model are indicated. In conclusion, brief conclusions are made about the most favourable normative model of interaction between subjects of educational activity.
\end{abstract}

Keywords: Distance learning, Generation "Z", Subjects of educational activity, Digital educational environment, Social responsibility.

\section{INTRODUCTION}

Currently, in modern society, there is a trend aimed at increasing the number of areas of knowledge, acquaintance with which is possible online. This fact has led to the development of various forms of distance education [1].

At the beginning of this year, the President's Message to the Federal Assembly was made, which raised the issue of the need to make changes to the national project "Education", and also called for "finding flexible solutions" that will allow us to begin the digital transformation of the national school fully, and the creation of a wide space for education [2].

The digitalisation of education not only has a positive impact on the development of society but can also have serious consequences. The digital environment has a negative impact, primarily on the socialisation of the individual.
The education digitalisation leads to the fact that of all the individual characteristics of the individual, only the intellectual component is involved. However, the technological advance makes a change to the Federal State Educational Standard, changes the approach to the types of educational programs and actively distribute acquire e-learning courses have more massive open online courses, actively develop distance learning - all this leads to new requirements and setting the other objectives of the study to the students and teachers.

The COVID-19 pandemic has a particular impact on increasing the pace of introduction of distance learning methods by society:

- Hasan Najmul and Yukun Bao note that about one and a half billion schoolchildren and university students suffer due to the closure of educational institutions [3];

- P. Scott Bracey claims that in the 6 months since the beginning of the "new normal", Americans have gained 
significant experience working, studying and communicating on the Internet [4];

- According to the information posted in the UNESCO Digital Library (UNESDOC), distance learning is a response to school closures - it is a set of state measures taken by educational institutions to enable them to continue their studies [5].

The imposed restrictions affected the entire educational process around the world, which led to the need to conduct training sessions in a remote format.

The Ministry of Science and Higher Education has implemented several organisational measures aimed at a full-fledged transition to distance learning. However, one of the main problems during the transition was the lack of any experience of teachers conducting classes in virtual space, the necessary equipment and methodological guidelines. Despite the existing difficulties in providing distance learning, a big step has been taken towards the transition to digital education $[6,7]$.

\section{RESEARCH METHODS}

Content analysis was used to determine the subjects of educational activities and features of learning in the digital educational environment.

To determine the goals of digital education and types of interaction - an expert survey of teachers engaged in educational activities (with at least 5 years of experience), heads of structural divisions and employees of the educational and methodological department.

To assess the level of social responsibility of subjects of educational activity-analysis of the results of activities in the digital educational environment.

\section{SUBJECTS OF DIGITAL EDUCATION}

At the moment, there are not enough scientific studies aimed at studying the impact of informatisation in the field of education on the socio-cultural side of the student. The environment determines how the student builds his conceptual apparatus in matters of relations to public life.

In this situation, the change of roles of subjects of the educational process is quite clearly traced. The teacher ceases to be a source of knowledge and its reproduction. It begins to play the role of a guide or guide. In the information space, it ensures the unity and systematisation of the knowledge obtained by students. It also tracks the formation of a holistic and consistent picture of disciplinary knowledge. One of the functions of the teacher does not change, namely, managing the motivation of students, adjusting their individual development trajectory: self-education, personal and professional growth [8].

At the moment, students are mostly representatives of the generation "Z" (born after 1995). The main difference between "Z" and previous generations is that it was entirely formed in the era of global informatisation and did not observe the world around it without a modern stack of network technologies. For this generation, information from the Internet is the most critical source of socio-cultural development, affecting all spheres of life, including education [9].

Let us highlight some features of the generation "Z":

- fluency in information technology;

— good assimilation of information;

— the presence of multitasking, which increases their speed;

- confidence;

- in general, the presence of your own opinion, after a situational analysis, etc.

These features are the basis of changes occurring in education [10].

\section{GOALS OF DIGITAL EDUCATION}

The digital educational environment allows you to quantitatively increase the functions of the teacher, as well as increase the speed of interaction between the subjects of the educational process. These opportunities are primarily used in the process of informatisation of education, and this does not lead to qualitative improvement. Along with specific opportunities for digital education, there are several problems and risks associated with the introduction of the education system:

1. The theory of digital learning, which teachers need to rely on when using distance learning, is not so profoundly developed.

2. Information is not synonymous with the concept of knowledge.

3. In most cases, the educational process is implemented through communication between the teacher and students.

A full-fledged transition to digital education can lead to the following consequences:

- Significantly increases the risk of speech degradation of students and as a consequence of thinking, since it is performed in speech. In the digital learning process, thinking can be reduced before the user presses a key, depending on the formation of responsibility among students. It is noted that in generation "Z", knowledge and judgments are superficial in more cases. When an individual does not have the practice of live 
communication, the lack of the ability to form and formulate their thoughts leads to slow development of thinking;

— digital learning has little to do with the parenting side. Education involves communication and interpersonal interaction of subjects of the educational process, the adoption of ethical and moral norms of society.

Thus, social responsibility comes to the foreground as one of the factors of the subjects of the educational process's adaptive potential in the transition to distance learning. Social responsibility is determined by the conscious regulation of educational subjects of their activities. We proceed from the fact that, according to Bayluk V.V., professional and personal growth, selfdevelopment depend, first of all, on the increase in the activity of self-education. Social responsibility is an integrative result, an indicator of education and a criterion for the formation of personal and professional subjectivity [11].

\section{MODELS OF INTERACTION OF SUBJECTS OF EDUCATIONAL ACTIVITY IN THE DIGITAL EDUCATIONAL ENVIRONMENT}

Several criteria can assess the level of formation of social responsibility among the subjects of educational activity. In our work, to identify the critical criteria, an expert survey was conducted based on the Moscow State Regional University. As experts, teachers engaged in educational activities (with at least 5 years of experience), heads of structural divisions and employees of the educational and methodological department were involved.

As criteria for the effectiveness of students' educational activities carried out in a digital educational environment, the following criteria were identified:

- comparison of work activity in online and offline mode (frequency and success of responses in online classes held on various platforms, such as Zoom, Skype, Mirapolis, etc. and offline classes held before switching to distance learning): 0 points-passive in classes, 1 pointactive for more than $30 \%$ of classes, 2 points-active for at least $50 \%$ of classes; 3 points-active for more than $80 \%$ of classes;

- attendance (attended less than $30 \%$ of classes-0 points; attended $30-50 \%$ of classes -1 point; attended 50$80 \%$ of classes -2 points; attended more than $80 \%$ of classes -3 points);

- completing tasks (did not start completing tasks - 0 points; completed less than $50 \%$ of tasks - 1 point; completed $50-80 \%$ of tasks; completed more than $80 \%$ of tasks -3 points);

- a time of submission of the completed task (did not provide- 0 points; provided work after the specified deadline-1 point; provided work close to the end of the deadline -2 points; provided work with a significant margin of time before the end of the task - 3 points).

Based on the criteria, the following results were obtained. (fig. 1.)

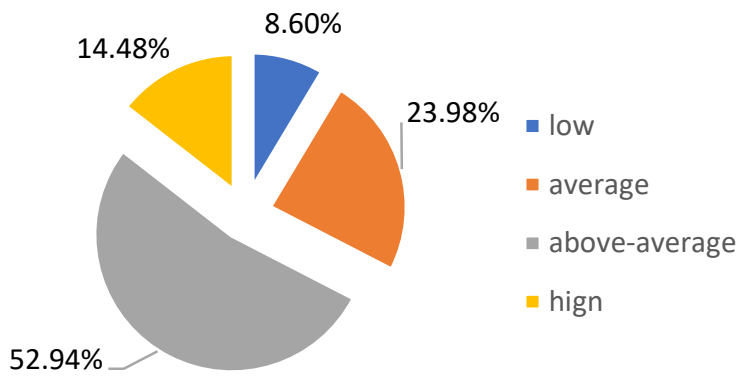

Figure 1 Distribution of the students' social responsibility level.

As criteria for the effectiveness of the implementation of educational activities by the teaching staff were identified:

- fullness of e-education environment content in the discipline (course not completed - 0 points; the course filled a minimum set of materials from RPD - 1 point; the material is presented in sufficient quantities -2 points; the material is presented in diverse forms -3 points);

- implementation of feedback with students (does not carry out -0 points; provides feedback as students' questions accumulate-1 point; provides feedback to students on time within the framework of EES - 2 points; provides feedback to students through all possible communication channels promptly -3 points);

- implementation of current control in the discipline (does not perform-0 points; verification is not carried out regularly - 1 point; current control is carried out regularly and on time -2 points; current control is carried out regularly, on time with detailed comments on completed tasks -3 points);

- conducting classes (classes are not held-0 points; classes are held-1 point; classes are held with the use of EEW - 2 points; classes are held with the involvement of the author's EEW - 3 points).

Based on the criteria, a ranking was carried out, after which students and teachers could score a certain number of points (0-12). According to the results of the analysis 
of the obtained data, it is possible to distinguish 4 levels of formation of social responsibility among students and teachers: low (0-3 points); medium (4-6 points); aboveaverage (7-9 points); high (10-12 points).

Further, the study analysed the activities of 17 teachers, considering the above criteria. The following results were obtained: 2 people have a low level of social responsibility, which was $11.76 \%$, average-3 (17.65\%), above-average -7 (41.18\%), high -5 (29.41\%) (fig. 2.).

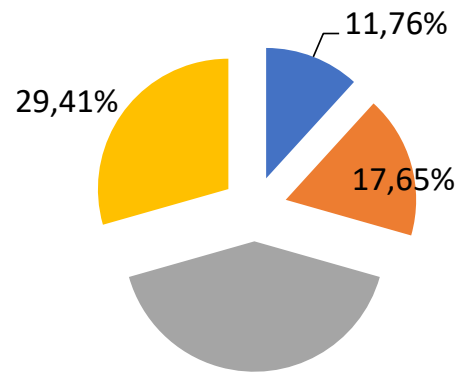

low
average
above-average
high

$41,18 \%$

Figure 2 Distribution of the social responsibility level among teachers.

At the next stage, one teacher of each level was selected. For each of them, groups of students with whom he carried out educational activities were identified. Based on this sample (221 students), an assessment of the responsibility of subjects of educational activities in the digital educational environment was made.

In each group of students, the average level of social responsibility was determined, based on the points obtained according to the above criteria, when mastering the discipline of each teacher.

These models of interaction were reinterpreted from the algorithms of adaptive interactions given in the work of Bulgakov A.V. [12] as follows: we consider some normative models of interaction in the "person $\leftrightarrow$ group" system. Similarly, the names of these models are formulated.

When drawing up models, the teacher is indicated by $\mathrm{T}$, the group of students is indicated by $\mathrm{G}$, and the lower indices indicate the corresponding levels of social responsibility.
1) forced interaction model;
2) counter interaction model;
3) resource interaction model;
4) background interaction model.

Let us describe some characteristic features inherent in each of the interaction models.

\section{Forced interaction model: $\left(T_{1} \leftrightarrow G_{4}\right.$ or $\left.T_{4} \leftrightarrow G_{1}\right)$;}

Active (subject) both the teacher and a group of students can act as a party in this interaction, setting the parameters of educational activity, which determines its spontaneous and reactive nature. The passivity of the parties to the interaction is situational.

Counter interaction model: $\left(T_{2} \leftrightarrow G_{2}\right.$ or $T_{2} \leftrightarrow G_{3}$ or $T_{2}$ $\left.\leftrightarrow G_{4}\right)$.

The active party in this normative model of interaction is not only the teacher who sets the parameters of educational activities, but also a group of students, which contributes to the creative collision of two activities, and the manifestation of these activities may not be codirected. This interaction can give rise to innovative activities. It is possible only in a situation where the level of social responsibility is high enough for a group of students to defend their interests in the implementation of educational activities. In this model, the features of subject-subject education are quite clearly manifested.

Resource interaction model: $\left(T_{3} \leftrightarrow G_{2}\right.$ or $T_{4} \leftrightarrow G_{2}$ or $T_{3}$ $\leftrightarrow G_{3}$ or $T_{3} \leftrightarrow G_{4}$ or $T_{4} \leftrightarrow G_{3}$ or $\left.T_{4} \leftrightarrow G_{4}\right)$.

One of the main components of this model of interaction can be considered the use of the entire variety of resources used in educational activities. It is also possible to distinguish such a feature as the presence of psychological comfort in the implementation of training. This contributes to the self-realisation of both sides of educational activities, which can also be considered the key to the formation of innovations. This normative model will have the features of subject-subject education.

Background interaction model: $\left(T_{l} \leftrightarrow G_{l}\right)$.

Participants in educational interaction are passive, so both sides of the educational process are reactive. These normative models reflect not so much the activity/reactivity dichotomy as the degree or possibility of innovative educational activity. When implementing this interaction, educational technologies that do not meet the conditions of the digital educational environment are used.

\section{CONCLUSIONS}

In this paper, a study was conducted to identify the levels of social responsibility of subjects of educational activities carried out in a digital educational environment, based on the selected criteria. The paper presents normative models of interaction between participants of the educational process.

In our opinion, the most favourable will be the presence in the educational organisation of a counter or resource model of interaction that contributes to the 
emergence of innovative activities that can lead to a qualitative change in education. Also, under certain circumstances, it is possible to implement a compulsory regulatory model of interaction, for example, at the stage of forming social responsibility. And when identifying the background model of interaction, it may be necessary to adjust the interaction, as well as analyse the causes and situations against which this model has developed.

\section{REFERENCES}

[1] The evolution of distance education in 2020. Retrieved from: https://educationonline.ku.edu/community/distance -education-evolution-in-2020

[2] Message Of The President to The Federal Assembly Retrieved from: http://www.kremlin.ru/events/president/news/6258 $\underline{2}$

[3] Hasan, Najmul, and Yukun Bao. "Impact of "eLearning crack-up" perception on psychological distress among college students during COVID-19 pandemic: A mediating role of "fear of academic year loss", "Children and youth services review Vol. 118 (2020) $105355 . \quad$ DOI: 10.1016/j.childyouth.2020.105355 Retrieved from: https://www.ncbi.nlm.nih.gov/pmc/articles/PMC74 22835/

[4] P. Scott Bracey, Tips for living online - lessons from six months of the COVID-19 pandemic. Retrieved from: https://theconversation.com/tips-for-livingonline-lessons-from-six-months-of-the-covid-19pandemic-145514

[5] Distance learning strategies in response to COVID19 school closures. Retrieved from: https://unesdoc.unesco.org/ark:/48223/pf00003733 05?posInSet=2\&;queryId=N-8ea77989-29de-4ff3997c-eaddc678be5b

[6] O.A. Kalimullina, I.V. Gaydamashko, Training of young specialists in the system of modern education: a vector of a multicultural paradigm. Kazan Pedagogical Journal 4(141) (2020) 66-71.

[7] Hasan, Najmul, and Yukun Bao. "Impact of "eLearning crack-up" perception on psychological distress among college students during COVID-19 pandemic: A mediating role of "fear of academic year loss"." Children and youth services review Vol. $118 \quad$ (2020) $105355 . \quad$ DOI: 10.1016/j.childyouth.2020.105355 Retrieved from: https://www.ncbi.nlm.nih.gov/pmc/articles/PMC74 $\underline{22835 /}$
[8] E.M. Klimova, A.A. Kamyshanov, S.A. Ognev, Psychological conditions for ensuring the effectiveness of methodological activities of university employees in the context of digitalisation of education. Psychology of learning 5 (2017) 138143.

[9] M.S. Yanitsky, Psychological aspects of digital education, Professional education in Russia and abroad 2(34) (2019) 38-44.

[10] P.A. Vysotskaya, Yu.D. Kuleshova, Distance learning - the skill of a teacher of the 21 st century, Collection of works of the department of mathematical analysis and geometry "actual problems of mathematics, physics and mathematical education" [electronic resource]: A collection of theses, ed. G.V. Kondratieva, N.N. Barabanova, E.A. Bedrikova, Moscow: Moscow state regional university, 2020. pp. 80-84.

[11] V.V. Bayluk, Education of students' social responsibility. Social responsibility: problems and ways of their solution: materials of the vii international social and pedagogical readings named after B.I. Livshits, Yekaterinburg, November 12-14, 2015; Ural State Pedagogical University, Yekaterinburg, 2015, p. 14-18.

[12] A.V. Bulgakov, Psychological theory and practice of intergroup adaptation, Monograph, Moscow: Moscow state regional university, 2006. 